\title{
TECNOLOGIAS NO PROCESSO DE ALFABETIZAÇÃO NOS ANOS INICIAIS DO ENSINO FUNDAMENTAL
}

\author{
TECHNOLOGIES IN THE LITERACY PROCESS IN THE FIRST YEARS OF FUNDAMENTAL \\ EDUCATION
}

\author{
TECNOLOGÍAS EN PROCESO DE ALFABETIZACIÓN EN LOS PRIMEROS AÑOS DE LA EDUCACIÓN \\ FUNDAMENTAL
}

\author{
Renato Pinheiro da Costa ${ }^{1}$ \\ Élida Estevão Cassimiro ${ }^{2}$ \\ Rozinaldo Ribeiro da Silva ${ }^{3}$
}

Submetido em: 24/07/2020 - Aceito em: 22/09/2020 - Publicado em: 25/01/2021

\begin{abstract}
${ }^{1}$ Possui graduação em Pedagogia pela Universidade do Estado do Pará-UEPA, Especialista em História e Filosofia da Educação pela Universidade Federal do Pará-UFPA, Mestre em Educação pela Universidade Federal do Pará -UFPA na linha de pesquisa Currículo e Formação de Professores; Doutor em Educação da linha de pesquisa Educação: Currículo, Epistemologia e História. Pesquisador do Grupo de Pesquisa: Ensino de História e Saberes Escolares (SABHER). Pesquisador do Grupo de Pesquisa: Núcleo de Estudos Pesquisas em Educação e Currículo-NEPEC. Líder do Grupo de Pesquisa: Grupo de Estudos e Pesquisas em História, Sociedade e Educação no Brasil-HISTEDBR/SECÇÃO ALTAMIRA-PA, com ênfase na investigação e estudo da História da Educação, História das Instituições Escolares, EJA, Tecnologia da Educação, Currículo e Formação de Professores. Professor do Programa de Pós-Graduação em Ensino de História (PROFHISTORIA) - Campus UFPA de Ananindeua. Professor da Faculdade de Educação - Campus UFPA de Altamira/Pa.
\end{abstract}

${ }^{2}$ Graduada em Pedagogia pela Universidade Federal do Pará. Campus de Altamira.

${ }^{3}$ Possui Graduação em Pedagogia (conclusão 1999) e Mestrado Acadêmico em Educação pela Universidade Federal do Pará (conclusão 2005). É professor efetivo da Universidade Federal do Pará/Campus Universitário de Altamira-UFPA/Faculdade de Educação na disciplina Política e Legislação da Educação entre outras. Foi Diretor da Faculdade de Educação e Coordenador do Programa de Formação de Professores/ParforPoloAltamira. É representante docente no Conselho Deliberativo do Campus de Altamira. Tem experiência em Educação Básica (Prefeitura Municipal de Altamira/Pa e SEDUC/Pa) e Superior, tendo sido Professor Substituto da Universidade Federal do Pará por duas vezes (nos campi de Soure, Breves, Itaituba, Altamira e Abaetetuba). Atua, principalmente, nos temas Trabalho, Educação e Saúde, Educação e Emancipação, Legislação Educacional, Política Educacional e Formação de Professores. Ocupou, também, o cargo de Assessor Técnico (Chefe de Gabinete) da Delegacia Regional do Trabalho no Pará (MTE/DRT/Pa), Assessor da Secretaria de Saúde do Sindicato dos Bancários do Estado do Pará. É pesquisador vinculado ao Grupo de Estudos e Pesquisas sobre Trabalho e Educação do Centro de Educação da Universidade Federal do ParáGEPTE/UFPA. Também é pesquisador cadastrado no Diretório do Grupo de Pesquisa do CNPq Trabalho, Educação e Educação Profissional. No Campus Universitário de Altamira, desenvolve Projeto de Pesquisa intitulado: A Situação de Trabalho dos Profissionais da Educação de Altamira. Na sua fase juvenill universitária, participou da organização politica da juventude altamirense, Foi membro do CA de Pedagogia e

\begin{tabular}{l|l|l|l|l|l|l|} 
(C) Redoc & Rio de Janeiro & v. 5 & n.1 & p. 97 & Jan/Abr 2021 & ISSN 2594-9004
\end{tabular}




\section{RESUMO}

Este trabalho apresenta como tema o uso das tecnologias no desenvolvimento do processo de alfabetização nos anos iniciais do ensino fundamental, objetiva discutir sobre a contribuição das tecnologias para o desenvolvimento do processo de alfabetização nos anos iniciais do ensino fundamental. No tocante da discussão foi possível identificar as tecnologias mais utilizadas como metodologias de ensino no processo de alfabetização e ao mesmo tempo, relatar os obstáculos existentes na prática educativa, quanto à utilização das tecnologias pelos professores na sala de aula destacando a importância dos materiais educativos digitais e práticas pedagógicas inovadoras para aperfeiçoar o processo de ensino e aprendizagem na alfabetização. Como metodologia pautamo-nos no método de pesquisa qualitativa com ênfase na pesquisa bibliográfica, onde autores como Santos (2010), Didonet (2003), Kenski (2011), Moran (2006) e Maesta (2011), foram utilizados como aporte teórico. Desse modo considerou-se que a tecnologia aplicada ao ensino escolar visa à consolidação da prática educativa de qualidade e promoção da democratização ao acesso à informação e ao conhecimento, além de melhorar os resultados diante o processo de ensino-aprendizagem no ensino fundamental.

PALAVRAS-CHAVE: Educação Básica. Tecnologia Educacional. Método de ensino.

\section{ABSTRACT}

This work presents as a topic the use of technologies in the development of the literacy process in the first years of primary school, aims discuss the contribution of technologies to the development of the literacy process in the early years of elementary school. Regarding the discussion, it was possible to identify the most used technologies as teaching methodologies in the literacy process and, at the same time, to report the obstacles that exist in educational practice, with respect to the use of technologies by teachers in the classroom, highlighting the importance of digital educational materials. And innovative pedagogical practices to improve the teaching and learning process in literacy. As a methodology, we are guided by the qualitative research method with an emphasis on bibliographic research, where authors such as Santos (2010), Didonet (2003), Kenski (2011), Moran (2006) and Maesta (2011), were used as a theoretical contribution. Therefore, it was considered that the technology applied to school education aims to consolidate quality educational practice and promote democratization in access to information and knowledge, in addition to improving results in the teachinglearning process in primary education.

KEYWORDS: Basic education. Educational Technology. Teaching method.

\section{RESUMEN}

Este trabajo presenta como tema el uso de tecnologías en el desarrollo del proceso de alfabetización en los primeros años de la escuela primaria, tiene como objetivo discutir la contribución de las tecnologías al desarrollo del proceso de alfabetización en los primeros años de la escuela primaria. Con respecto a la discusión, fue posible identificar las tecnologías más utilizadas como metodologías de enseñanza en el proceso de alfabetización y, al mismo tiempo, informar los obstáculos que existen en la práctica educativa, con respecto al uso de tecnologías por parte de los docentes en el aula, destacando la importancia de los materiales educativos digitales. Y prácticas pedagógicas innovadoras para mejorar el proceso de enseñanza y aprendizaje en alfabetización. Como metodología, nos guiamos por el método de investigación cualitativa con énfasis en la investigación bibliográfica, donde autores como Santos (2010), Didonet (2003), Kenski (2011), Moran (2006) y Maesta (2011), fueron utilizados como una contribución teórica. Por lo tanto, se consideró que la tecnología aplicada a la educación escolar tiene como objetivo consolidar la práctica educativa de calidad y promover la democratización en el acceso a la información y el conocimiento, además de mejorar los resultados en el proceso de enseñanza-aprendizaje en la educación primaria.

do Diretório Acadêmico do Campus, representando os estudantes nos 44, 45 e 46 Congressos da União Nacional dos Estudantes/UNE

\begin{tabular}{l|l|l|l|l|l|l} 
(C) Redoc & Rio de Janeiro & v. 5 & n.1 & p. 98 & Jan/Abr 2021 & ISSN 2594-9004
\end{tabular}


PALABRAS CLAVE: Educación básica. Tecnologia Educacional. Método de enseñanza.

\section{INTRODUÇÃO}

A escola, dentre suas finalidades, destina-se a socializar o conhecimento, os princípios teóricos e metodológicos socialmente construídos, de modo que os alunos encontrem condições necessárias para pensar, fazer, experimentar, discutir, analisar e descobrir. Assim o conhecimento é instrumento para as realizações profissionais dos alunos, a fim de ocuparem seus espaços na sociedade.

Tendo como objetivo geral discutir a contribuição das tecnologias para o desenvolvimento do processo de alfabetização nos anos iniciais do ensino fundamental. Nesse processo estaremos identificando os recursos tecnológicos mais utilizados como metodologias de ensino no processo de alfabetização, desse modo teremos subsídios para relatar os obstáculos existentes na prática educativa, quanto à utilização das tecnologias pelos professores na sala de aula e destacar a importância dos materiais educativos digitais e das práticas pedagógicas tecnológicas inovadoras para aperfeiçoar o processo de ensino e aprendizagem nas series iniciais.

Pretende, essencialmente, apresentar o uso das tecnologias na educação como um dos meios pelo qual se possibilita um processo de ensino-aprendizagem com qualidade e potencialidade, a fim de atender as necessidades dos alunos e comunidade escolar, com a identificação das perspectivas e desafios para a sua consolidação, a partir da formação de sujeitos críticos, participativos nas transformações de sua realidade, como consequência de uma nova prática educativa que ajude na constituição de um cidadão capaz de atuar na sociedade em que está inserido. Desse modo, esse processo deve ser realizado através da participação de todos os atores ligados à comunidade escolar.

A escolha desse tema ocorreu pelo fato de que o uso de diversos recursos tecnológicos no contexto educacional, como a internet, tende a proporciona um ensino mais dinâmico e inovador, além de ser uma das várias ferramentas de grande importância para o enriquecimento das aulas no processo de alfabetização. Mas para isso há necessidade de formação e ou preparação de professores para utilizar com responsabilidades as tecnologias na sala de aula.

Assim, o foco principal desta investigação é uma reflexão quanto às questões relativas à utilização das tecnologias na prática educativa da sala de aula, com vistas ao melhor desenvolvimento de estratégias a fim de colaborar na construção de um ensino de qualidade. Como hipótese, apontou-se que o uso das tecnologias denota novas ações dentro do âmbito escolar, desde que esteja inserido de forma apropriada no processo ensino aprendizagem.

Quanto à metodologia foi utilizada a pesquisa bibliográfica, no sentido de identificar os 
objetivos propostos, pesquisa de cunho qualitativo, as melhores produções foram selecionadas com base em critérios relacionados à qualidade acadêmica apresentada pela produção e periódicos e pelo alinhamento dos mesmos ao tema e aos objetivos proposto, se concorda com os autores Marconi e Lakatos (2006, p. 71), ao afirmarem que "a pesquisa bibliográfica não é mera repetição do que já foi dito ou escrito sobre certo assunto, mas propicia o exame de um tema sob um novo enfoque ou abordagem, chegando à conclusões inovadoras". Para isso, utilizaram-se discussões teóricas de autores como Santos (2010), Didonet (2003), Kenski (2011), Moran (2006), Maesta (2011), entre outros, ao apresentarem sobre a importância das tecnologias para o desenvolvimento e aperfeiçoamento da leitura e escrita, com vistas ao sucesso da aprendizagem nos primeiros anos do ensino fundamental.

Este trabalho contribui para aumentar as discussões quanto às práticas pedagógicas e a utilização das tecnologias, inseridas de forma apropriada no processo ensino aprendizagem para o desenvolvimento integral das crianças, bem como a preparação dos professores para a execução de atividades tecnológicas educativas dinâmicas e condizentes ao ensino de qualidade e satisfatório, de modo que atenda as necessidades e especificidades da comunidade escolar, que possibilite às crianças um ensino que os capacitem para atuarem como sujeitos de sua própria história.

Nessa dinâmica, o professor aprimora suas metodologias, por meio das mais variadas tecnologias, as quais motivam os alunos através de aulas mais dinâmicas e atrativas, com a utilização de ferramentas tecnológicas como computador, internet, televisão, DVD, entre outros, uma vez que estas ferramentas estão presentes no cotidiano das crianças, jovens e adultos, que as utilizam em grande parte do dia como meio de comunicação, entretenimentos, pesquisas etc., possibilitando muitos benefícios, nesse sentindo, utilizando adequadamente, funciona como uma grande fonte metodológica no processo ensino aprendizagem.

\section{Tecnologias e suas relações com a escola}

A educação é o processo que apresenta entre seus muitos objetivos, possibilitar a formação da cidadania e garantir a igualdade social por intermédio do processo ensino-aprendizagem, através do desenvolvimento integral do potencial humano desde o nascimento até o fim da vida. Assim sendo, assume lugar de destaque no panorama das políticas públicas governamentais, para que todos tenham acesso ao ensino de qualidade (MAESTA, 2011).

No entanto, essas ações ainda não possibilitaram o cumprimento dos compromissos firmados na Constituição Federal de 1988 (BRASIL, 1988, p. 125-126): “erradicação do analfabetismo, universalização do atendimento escolar, melhoria da qualidade de ensino, formação para o trabalho e promoção humanística, científica e tecnológica do país”. Dessa forma, tal situação provocou início da luta da sociedade brasileira pela universalização do atendimento escolar que se remota há décadas, mesmo porque essa universalização do acesso à escola está garantida por lei, de tal forma, que a educação assim está segurada no artigo 205 da CF/88: "A educação direito de todos e dever do Estado e da família, será promovida e incentivada com a colaboração da sociedade, visando ao pleno desenvolvimento da pessoa, seu preparo para o exercício da cidadania e sua qualificação para o trabalho" (BRASIL, 1988, 


\section{p. 123).}

Isto exposto é de conhecimento notório que a educação é um diferencial da civilização humana, cuja meta é promover a formação integral dos homens a partir dos primeiros anos de vida até sua vida adulta quando será capaz de resolver problemas e assumir seus espaços na sociedade e a instituição escolar é a principal responsável por esses compromissos. Sobre isso, Libâneo (2007, p. 309) afirma que: "o grande objetivo das escolas é a aprendizagem dos alunos, e a organização escolar necessária é a que leva a melhorar a qualidade dessa aprendizagem". Nesse contexto, a escola necessita redimensionar a sua prática, enquanto local de produção do saber científico e tecnológico, haja vista o seu papel na preparação do cidadão para atender às novas exigências do mundo do trabalho e promover um ensino de qualidade a todos os cidadãos.

O homem passou a planejar, elaborar, aperfeiçoar e construir as ferramentas, resultando no surgimento das tecnologias, em função do aperfeiçoamento das ferramentas, que ocorreu em três fases: primeiro, o homem selecionou paus e pedras para serem utilizadas nas atividades de caça, de pesca e defesa. Em seguida, o homem guardou algumas dessas peças para serem usadas em outras necessidades de usos específicos. Por fim, o homem passou a fabricar os instrumentos como cópias dos instrumentos originais e posteriormente passou a construir modelos padronizados, fazendo uma diferenciação das ferramentas (KENSKI, 2011).

Com a Revolução Industrial ocorreu o avanço tecnológico com o surgimento das fábricas, os quais muitas máquinas foram construídas no sentido de melhorar a produção industrial e consequentemente a margem de lucros. Entretanto, a partir do século XIX, a tecnologia ganhou destaque, devido seu aperfeiçoamento nos campos do conhecimento e comunicação, em resposta à necessidade de dinamizar os trabalhos desenvolvidos em todas as áreas da ação humana. As tecnologias de multimídias como o rádio, a televisão e o telefone surgiram para aperfeiçoar e integralizar várias regiões diferentes, divulgando informações e entretenimento, além das indústrias utilizá-las para vender seus produtos.

Atualmente vive-se o período da informação, intensificando a revolução tecnológica mundial, influenciando positivamente nas organizações sociais, na política e especialmente na economia através da globalização de conhecimentos e informações. Desse modo, cada vez mais o avanço tecnológico possibilitou crescimento, cultural, sócio e econômico às populações nas mais diversas regiões do planeta, pois não é necessário saí de suas casas para comprar produtos de outras cidades ou continentes, bem como realizar cursos de formação profissional, sem frequentar fisicamente uma instituição. Nessa dinâmica, são diversas as formas de conceituar as tecnologias, as quais tecnologicamente significam (tecno $=$ técnica + logia $=$ ciência), funcionando como estratégias, métodos e técnicas humanas, no sentido de potencializar suas ações em todos os campos de atuação como na comunicação, comércio e educação, desenvolvidos de forma agradável e dinâmica. A expressão "tecnologia" diz respeito a muitas outras coisas além de máquinas. O conceito de tecnologias engloba a totalidade de coisas que a engenhosidade do cérebro humano conseguiu criar em todas as épocas, suas formas de uso, suas aplicações (KENSKI, 2011, p. 22-23). 
Desse modo, por toda a história o homem criou diversas formas de comunicação e tecnologias, as quais se modificam ao longo dos anos desde desenhos arqueológicos da Idade Antiga à internet da atualidade. Os meios de comunicação permitem a comunicação entre pessoas e possibilitam a transmissão de informações e entretenimento, através de diálogo e a troca de informações entre pessoas, além de serem fundamentais para a divulgação das informações e para as atividades econômicas. Nessa dinâmica, apresentam-se o jornal, pois através deste, seja escrito ou falado, suas informações são transmitidas, simultaneamente, às diversas regiões do país ou do mundo, a radiodifusão, pela qual as notícias e entretenimentos são repassados a diversos locais ao mesmo tempo, telefone, que possibilita a troca de diálogo e informação entre duas pessoas em diferentes lugares, telefone celular, pelo qual ocorre a troca de diálogo, informação, imagens e vídeos entre duas pessoas em diferentes pontos e a rede de internet, que na atualidade é o meio tecnológico mais utilizado e fundamental para as áreas do conhecimento, da comunicação e muitos outros fins (MAESTA, 2011).

Diante destes fatos, é importante destacar que o homem, ao longo da história, utilizou de sua inteligência e faculdades mentais, para desenvolver técnicas e objetos, no sentido de superar as dificuldades cotidianas, também com vistas a potencializar as ações humanas nas mais diversas áreas do conhecimento. Dentre essas invenções tecnológicas, de acordo com Kenski (2011), atualmente merece destaque a rede de internet, a qual funciona com base principal para o funcionamento de muitas outras invenções, possibilitando com mais velocidade o conhecimento e informações a milhares de pessoas, em todas as partes do planeta e de forma simultânea. Assim, é notório registrar que estes avanços se tornam mais expressivos e inovadores a cada ano, sobretudo nesta segunda década do século XXI, mascada pelo aceleramento da tecnologia eletrônica, com atenção especial para a informática, os celulares smartphones, o computador e a internet.

No ambiente escolar, todas as atividades administrativas e pedagógicas desenvolvidas, devem estar baseadas no projeto político-pedagógico (PPP), o qual segundo Libâneo (2004) precisa determinar os objetivos, diretrizes e as ações a serem executadas no ambiente escolar, mas sempre obedecendo às normas e a legislação do sistema de ensino, bem como as expectativas da comunidade escolar. Nesse sentido, a Lei de Diretrizes e Bases (LDB) 9.394/96, no inciso I do Artigo 12 estabelece que, "Os estabelecimentos de ensino, respeitadas as normas comuns e as do seu sistema de ensino, terão a incumbência de: I - elaborar e executar sua proposta pedagógica”. Desse modo, na elaboração do PPP é necessária a reflexão e debate democrático feito por todos os envolvidos no processo educacional. Assim, a escola estará obedecendo a sua função democrática na formação de cidadãos, críticos, criativos e capazes de resolver seus problemas de modo a satisfazer seus desejos e os desejos do grupo em que estão inseridos, desenvolvendo uma consciência de cidadania, de direitos e deveres e, de respeito mútuo (BRASIL, 1996).

A escola precisa mobilizar-se para atender a todos para isso precisa definir uma metodologia de ensino por meio das ferramentas tecnológicas e desse modo, os professores terão a segurança para desenvolver suas atividades educativas e promover um ensino dinâmico e divertido aos alunos. Mas, para isso faz-se necessário também à elaboração de cursos de formação continuada aos professores quanto à utilização da tecnologia como metodologia de 
aprendizagem, visto que, a grande maioria desses profissionais escolares não obteve formação acadêmica suficiente sobre esse tema. Assim o PPP da escola precisa apresentar a tecnologia como um dos pilares da tomada de decisões para uma aprendizagem dinâmica, que atenda a todos os alunos, bem como aperfeiçoar espaços, recursos e essencialmente desenvolver um currículo amplo, flexível e aberto englobando os aspectos cognitivos, afetivos e sociais da formação humana. Isso ocorre através de um excelente projeto pedagógico que prioriza a tecnologia, com o trabalho conjunto de professores, funcionários da escola, familiares e membros da comunidade escolar que se colocam à disposição, com atividades expositivas e culturais extracurriculares, com a avaliação do processo em uma ação de feedback (VEIGA, 2001).

Nesta perspectiva, a inserção de práticas pedagógicas tecnológicas na alfabetização e no currículo, faz se necessário para uma reorganização nos processos de aprendizagem, visto que a Tecnologia Educacional efetua essa reorganização através de concepções educativas e didáticas, por meio de um processo comunicativo, com olhar especial aos meios, ou seja, numa perspectiva instrumental tecnológica que se relacionam com as estruturas cognitivas do sujeito. Desse modo, Silva (2002, p. 67), destaca que "as relações entre "tecnólogos" e "curricularistas" devem ser abertas e simplificadas, concorrendo mutuamente para a análise e reorganização dos processos de aprendizagem. " Neste sentido, de acordo com Silva (2002) o emprego das Tecnologias Educacionais no currículo e na alfabetização são inquestionáveis, de modo que, surgem constatações das necessidades de novas práticas pedagógicas tecnológicas que visa beneficiar o desenvolvimento do processo de ensino e aprendizagem, visto que, tende a aprimorar e tornar a aprendizagem mais atrativa, com práticas estimulantes e significativas.

\section{A importância da formação docente para interação com as tecnológicas educacionais no processo de alfabetização}

Ao realizar uma reflexão sobre a formação de profissionais escolares a fim de atuarem com os recursos tecnológicos, faz-se necessário frisar que os professores, ao final de suas formações acadêmicas, geralmente não têm conhecimento quanto à utilização e manuseios dos novos recursos tecnológicos na sala de aula. Isso foi uma consequência do crescente avanço das ferramentas tecnológicas a cada ano e a grande maioria dos professores, em atuação hoje, concluíram seu curso superior em uma época em que iniciava a invenção do celular e propagação da internet e seus materiais afins como os computadores. Assim, Libâneo (2007, p. 309), afirma que "o grande objetivo das escolas é a aprendizagem dos alunos, e a organização escolar necessária é a que leva a melhorar a qualidade dessa aprendizagem”.

Diante destes fatos, o governo federal, percebendo a grande dificuldade dos professores em utilizarem os recursos tecnológicos e em sala de aula, criou e disponibilizou para as escolas públicas do país o Programa Nacional de Tecnologia Educacional (PROINFO), no ano de 1997, com o objetivo primordial promover o uso pedagógico das tecnologias de informática e comunicações (TICs) na rede pública de ensino fundamental e médio, bem como a formação e capacitação dos professores para atuarem com os recursos tecnológicos em sala de aula. Em sua prática, o Governo Federal, por meio desse programa entrega às escolas públicas 
brasileiras computadores, recursos digitais e conteúdos educacionais, ao passo que os estados, o Distrito Federal e os municípios, em contrapartida precisam construir e garantir a estrutura adequada logística para receber os laboratórios e capacitar os educadores para uso das tecnologias (PROINFO, 2000).

Por conseguinte, os cursos de formação continuada para os professores, como mediadores no processo de formação do indivíduo, para atuar nessa sociedade de constantes inovações, é um grande desafio compreender as ferramentas tecnológicas durante o processo de ensinoaprendizagem. Assim, uma vez oferecidos esses cursos, fazem-se necessário à disponibilidade e a flexibilidade da equipe de professores para aprender com todas as formações e informações ofertadas pela equipe diretiva da escola, pois a formação docente exige fundamentação teórica, instrumentalização técnica e sensibilidade quanto às ações subjetivas inerentes ao uso das tecnologias na prática educativa que Perrenoud (2000) sinaliza para o desenvolvimento educacional. Nessa perspectiva, ao tratar do assunto da introdução das tecnologias educacionais no meio dos educandos Almeida (2000) frisa a importância da preparação dos educadores quanto ao uso dessas tecnologias para formação do aluno que por sua condição socioeconômica por vezes não tem familiaridade com os recursos tecnológicos digitais devido ao pouco acesso aos equipamentos.

Desse modo, a formação continuada dos professores em relação às práticas pedagógicas tecnológicas, é de extrema importância e totalmente essencial, pois de acordo com a autora, os alunos tendem a ter mais facilidade no manuseio de algumas tecnologias que alguns professores, devido terem nascido na era tecnológica e consequentemente terem acesso, de tal modo, liberado, o que muitos educadores em sua formação não tiveram, por isso a necessidade de formação continuada para os professores, até para poderem orientar seus alunos, quanto à utilização desses recursos tecnológicos de forma consciente, em beneficio ao seu desenvolvimento no processo de alfabetização.

Seguindo essa linha de raciocínio, sendo o professor, o principal mediador no processo ensino-aprendizagem, como nos apresenta Libâneo (2007, p. 310) "o exercício profissional do professor compreende, ao menos, três atribuições: a docência, a atuação na organização e na gestão da escola e da produção de conhecimento pedagógico", é primordial que este profissional da educação saiba utilizar as tecnologias, no sentido de investigar e discernir formas para potencializar a apresentação do conhecimento aos alunos, através das inovações no ato de ensinar como enfatiza Moran (2000).

Assim, em meio a tantas informações no mundo virtual e devido a grande rapidez que as mesmas são atualizadas, é um grande desafio para educador escolher e orientar seus alunos nas suas escolhas de informações para debates e absorção, é necessário da ênfase na veracidade e em autorias corretas e confiáveis, priorizando as informações importantes, tornando a busca pelo conhecimento relevante e significativa.

Andrade (2011), defende a ideia de que são muitos os obstáculos referentes ao processo de formação continuada aos professores para manusear e entender as ferramentas tecnológicas, posto que a maioria desconheça como adaptá-las à aprendizagem. No entanto, é importante 
que o professor conheça e avalie o potencial das ferramentas tecnológicas, a fim de que os alunos as utilizem dentro e fora da sala de aula de maneira responsável e consciente, na construção do conhecimento, posto que ao seu alcance e oportuniza o uso consciente por seus alunos, com o objetivo de envolvê-los e apoiá-los na alfabetização. Caso o professor não esteja preparado, a escola não responderá com eficácia, quanto à utilização das tecnologias como metodologia de ensino.

Nessa perspectiva, a formação docente deve estar ligada sempre ao sistema básico de ensino, colaborando e consolidando sua formação teórica com as práticas do dia a dia do educador nas instituições, desenvolvendo a troca de saberes educacionais da região em que está inserido e consequentemente ampliando suas visões quanto a questões socioambientais, diversidade étnico-racial, gênero, sociocultural, entre outros. Desse modo, Azanha (2004) destaca a amplitude de informações a serem trabalhadas na formação docente assumindo a dualidade da teoria e prática, abrangendo diferentes realidades da sociedade e culturas nela existente. Nesse sentindo, a formação continuada se faz necessária mais uma vez, haja vista, seu intuito, abranger assuntos a qual a sociedade atual está inserida, deixando os professores aptos para um bom desenvolvimento na vida escolar.

Diante desse cenário, a incorporação das novas tecnologias de informação e comunicação surgem como um novo paradigma, como afirma Mercado (1998), por isso, as instituições de ensino ainda hoje em dia enfrentam desafios para a consolidação de ferramentas tecnológicas dentro âmbito escolar, para a realização de atividades e principalmente para torná-las conteúdos de ensino, o que acarreta em obstáculos, principalmente na formação do professor.

Nesse sentindo, o autor relata as dificuldades existentes na formação do educador, no entanto, aqueles que desejam avançar seus conhecimentos e manter-se atualizados quando a informações relevantes para a sociedade atual, precisam procurar por uma especialização específica ou pós-graduação. No mais, com base nos autores citados no corpo desse texto, identifica-se a falta de preparação de alguns professores, para atuarem na realidade atual do cotidiano escolar, por falta de políticas públicas e até mesmo tempo para a realização de um curso específico, no entanto, essa preparação, ou melhor, a formação continuada para os professores, é essencial, visto que, atualmente estão inseridos diversos assuntos complexos no cotidiano escolar, inclusive o uso das tecnologias, que necessita ser inserido como método pedagógico em auxilio e benefício da alfabetização e formação integral do educando.

A tecnologia está cada vez mais presente no dia a dia do indivíduo, sob a exigência do atual contexto socioeconômico, o qual visa sempre mais a aquisição de diversidade e inovações de técnicas e recursos tecnológicos cada vez mais velozes e eficazes para o atendimento do mundo capitalista, sempre na busca por lucros. Por isso, as tecnologias na educação se tornaram importantes, uma vez que pode tornar as aulas mais atrativas e diferenciadas, tornando-se um recurso que ajuda o professor a criar facilidades de aprendizagens, com o uso de jogos interativos que despertem o interesse do aluno. Os recursos tecnológicos também auxiliam o professor em questões de difícil execução, com ideias que podem ser utilizadas pelo professor, buscando a melhor forma de ensinar e aprender, como enfatiza Andrade (2011). 
Desse modo, a tecnologia assumiu espaço, rapidamente, no campo educacional, sendo utilizada como um instrumento para o processo de ensino-aprendizagem, a fim de garantir um ensino dinâmico e atualizado, resultando na produção do conhecimento, de forma rápida e positiva, pois, como afirma Moran (2000, p. 63), "ensinar com as novas mídias será uma revolução se mudarmos simultaneamente os paradigmas convencionais do ensino, que mantêm distantes professores e alunos. "Com isso é necessário investigar com uma perspectiva psicopedagógica, quanto à relação interpessoal entre professores e alunos, haja vista a forma dessa relação influência negativa ou positivamente no processo de ensinoaprendizagem.

Nesse mesmo pensamento, Almeida (2000), defende que a parceria entre a tecnologia e a educação, possibilita a transmissão e o aperfeiçoamento do conhecimento, uma vez que segundo esse mesmo autor, no sistema educacional é possível à utilização de muitas ferramentas tecnológicas como, a internet, o rádio, o ensino à distância, a televisão, a fotografia, o cinema, vídeos, computadores, teleconferência, lousa digital, tabletes, celulares, data show, pen drives, impressoras, entre outras, somadas às tecnologias tradicionais como o giz, lousa, livros, cadernos e carteiras escolares.

No mais, o computador, com sua grandeza de funcionalidades, é um aliado muito importante para o desenvolvimento do processo de alfabetização, o mesmo disponibiliza um leque de funções a favor do desempenho escolar, com programas e recursos que possibilita mudanças e inovações nas atividades desenvolvidas em sala de aula, despertando a curiosidade e o interesse dos educandos para as atividades propostas.

As ferramentas tecnológicas utilizadas no processo de ensino-aprendizagem, como a internet, assumem lugar de destaque, uma vez que possibilita aos alunos a aprendizagem tanto na sala de aula, quanto fora dela. Para Moran (2000, p. 53), "a internet é uma mídia que facilita a motivação dos alunos, pela novidade e pelas possibilidades inesgotáveis de pesquisa que oferece". Por meio deste importante recurso tecnológico, muitos outros estão interligados, em uma velocidade, pela qual as informações e a comunicação entre as pessoas são obtidas de forma instantânea, através de sites de buscas, relacionamentos, os fóruns, os chats e os blogs pessoais e institucionais. No entanto, faz-se necessário a atuação dos professores no que se refere à informação e orientação aos alunos sobre as vantagens e desvantagens da utilização da internet e sobre os perigos que ela oferece, de modo que todos saibam discernir aquilo que realmente é positivo para sua formação.

Nessa perspectiva, Maesta (2011) frisa que essas novas tecnologias se destinam ao maior desempenho e agilidade na atuação do professor, no desenvolvimento de suas atividades, bem como dinamizar a prática educativa e tornar um ensino mais atrativo e gratificante na visão dos alunos. Assim, é necessária a existência de políticas públicas para garantir à escola a apropriação destas novas ferramentas para que os professores, alunos, gestores e comunidade possam utilizá-las na perspectiva da relevância social a que elas se propõem. Também segundo a mesma autora, inovações tecnológicas transformaram positivamente o sistema educacional, no que se refere, provocando revoluções no método de ensinar, especialmente 
com a criação do computador e da comunicação digital, ferramentas tecnológicas bastante presente nas atividades educativas, a fim da promoção de melhores resultados no processo de ensino-aprendizagem.

Entretanto, para a concretização dessa realidade, faz-se necessário o aprendizado tecnológico, conforme afirma Kenski (2011, p. 41) "Já não há um momento determinado em que qualquer pessoa possa dizer que não há mais o que aprender. Ao contrário, a sensação é a de que quanto mais se aprende mais há para estudar, para se atualizar". Assim, a tecnologia tem função primordial de contribuir com a formação integral dos alunos a fim de estarem aptos ao desenvolvimento de inovações tecnológicas, com destaque para o manuseio do computador e a internet, a fim de despertar a sua curiosidade e o interesse na descoberta de novos conhecimentos.

De acordo com Kenski (2011), destacamos que é importante afirmar que nos últimos anos, foram muitos os recursos tecnológicos e audiovisuais utilizados em sala de aula, colaborando para um melhor rendimento e aproveitamento escolar aos alunos, uma vez que as aulas ficam mais interessantes, dinâmicas e criativas na visão dos mesmos. É a oportunidade para a escola aproveitar uma metodologia pedagógica complementar como videogame, DVD, dos jogos em rede, que já são usados pelos alunos fora da escola e desse modo desenvolver o processo de ensino-aprendizagem de forma interessante na visão dessa clientela.

Embora se observe que desde os primórdios da história se fala em tecnologia a partir da criação de ferramentas de trabalhos na Antiguidade, foi nas últimas décadas que os recursos tecnológicos ganharam destaque no meio sociocultural, econômico e educacional. Por isso, para Andrade (2011), o computador e a internet, por exemplo, são hoje os meios tecnológicos mais dinâmicos e atuais, onde professores e alunos podem encontrar informações desde fatos acontecidos a centenas de anos como fatos acontecidos há cinco minutos, onde se pode fazer o intercâmbio de informações com pessoas de todas as faixas etárias em qualquer lugar do mundo, dentre tantas outras possibilidades que o professor poderá adaptar ao dia a dia em sala de aula, desde que haja o preparo ou capacitação para a utilização destas e outras ferramentas tecnológicas.

\section{As tecnologias pedagógicas no processo de alfabetização dos anos iniciais do ensino fundamental}

Como se observou no capítulo anterior, as tecnologias são importantes na prática educativa, no sentido de facilitar a aprendizagem, mediante a utilização de recursos materiais, com o intuito de chamar a atenção das crianças para o conteúdo que está sendo ensinado, resultando em maior segurança no meio social e compreensão da realidade, bem como aptidão para que os indivíduos pratiquem seus direitos, trabalhando e integrando a sociedade com cidadania, inovando e buscando por conhecimentos sempre. Assim, é importante enaltecer a importância de se desenvolver nos primeiros anos escolares, uma prática educativa dinâmica, flexível com a utilização de recursos tecnológicos e lúdicos que visam estimular as crianças no processo de alfabetização, de forma diversificada e assim colaborar na formação de sujeitos críticos, uma vez que segundo Freire (2005) a leitura do mundo precede a leitura da palavra, ou seja, a 
leitura das palavras na escolarização.

Essa ação exige que a escola desenvolva um trabalho dinâmico e flexível, com a utilização de recursos tecnológicos, para atender as especificidades das faixas etárias infantis, ou seja, trabalhar com conteúdo de naturezas diversas que abrangem desde cuidados básicos, essenciais, até conhecimentos específicos provenientes das diversas áreas do conhecimento. Para tanto, é necessária uma formação profissional adequada, além de manter um diálogo constante sobre sua prática, com as famílias e a comunidade, visando um ensino de qualidade às crianças (BRASIL, 1998).

Sobre a importância da utilização dos recursos tecnológicos na dinâmica escolar, Pretto (1999, p. 104) afirma que "em sociedades com desigualdades sociais como a brasileira, a escola deve passar a ter, também, a função de facilitar o acesso das comunidades carentes às novas tecnologias". Isto porque nas famílias carentes, a escola pública é o único local que as crianças têm acesso às tecnologias de informação, entre outras. Nessa realidade é importante refletir quanto à prática pedagógica alicerçada nas tecnologias como estratégias fundamentais para o desenvolvimento da criança, com destaque para a linguagem oral e escrita, visando à formação integral, de modo flexível e dinâmico, preparando cidadãos para a vida e para às necessidades comerciais e econômicas da sociedade, primando sempre por um "trabalho informatizado, automatizado, escritórios virtuais em tempos, de menos deslocamentos e mais interação" (PRETTO, 1999, p. 105).

É fundamental que a instituição escolar corresponda essa nova realidade, atendendo aos interesses dos estudantes que anseiam por um ensino baseado nos avanços tecnológicos, mesmo porque, a escola não ficará às margens do mundo tecnológico globalizado. Desse modo, a instituição de ensino promoverá um ensino mais atraente e facilitador da aprendizagem, pois as crianças aprendem melhor e apresentam maior atenção aos conteúdos ensinados, quando estes são desenvolvidos a partir da utilização de recursos tecnológicos acessíveis aos alunos como, por exemplo, os celulares, câmeras digitais, televisão interativa, tablets, notebooks, computadores, internet sem fio (wi-fi), livros digitais, entre outros.

A utilização desses recursos tecnológicos tem impacto positivo em todo o processo de aprendizagem em sala de aula, com melhores índices de aprendizagem, maior atenção e motivação dos alunos pelo conteúdo ensinado, potencializando o desenvolvimento da leitura e escrita. Como também incentiva os professores a explorar todas as atividades possíveis a partir destes recursos, mas para isso, é necessário que a instituição escolar garanta a disponibilidade dos mesmos, especialmente os computadores e a rede de internet de qualidade. A aprendizagem da linguagem oral e escrita, conforme Piaget (1990) é um fator primordial ao oferecer as crianças possibilidades para desenvolver suas habilidades e participação das diversas práticas sociais, pois é por meio da linguagem que as pessoas interpretam e representam os acontecimentos de seu meio social.

Lajolo e Zilberman (1996) concebem a leitura oral e escrita imprescindível para a existência humana, por isso, no contexto escolar a prática educativa precisa ser baseada na dinâmica e flexibilidade associada à metodologia lúdica, com destaque para os recursos tecnológicos 
melhoram significativamente a aprendizagem dos alunos, haja vista, que as crianças aprendem com maior facilidade brincando. Com isso, a prática educativa deverá estar focalizada no aprimoramento das habilidades e potencialidades das crianças para a aprendizagem da leitura e escrita, haja vista que "Ninguém nasce sabendo ler, aprende-se a ler à medida que se vive. Se ler livros geralmente se aprende nos bancos da escola, outras leituras se aprendem por aí, na chamada escola da vida [...]" (LAJOLO, 2005, p. 07).

O professor deve manter o ambiente de ensino-aprendizagem dinâmico e adequado para estimular as crianças a praticarem a leitura e a linguagem oral de forma espontânea e divertida, identificando melhor a importância social da linguagem, uma vez que é primordial ensinar as crianças à diversidade do uso da fala com maior segurança e competência, função que segundo Brasil (1998) deve ocorrem em um ambiente seguro e adequado, que neste caso é a escola, que deve possibilitar às crianças atividades pedagógicas que potencializam o desenvolvimento leitura e escrita, dentro e fora da sala de aula, nos demais ambientes pedagógicos, com a utilização de práticas linguísticas dinâmicas e prazerosas do ponto de vista das crianças, colaborando no desenvolvimento do processo de alfabetização, destacando as tecnologias de multimídias e a busca das informações.

A questão da escrita nos primeiros anos escolares é uma consolidação da linguagem oral por meio da leitura, sendo que a escrita é considerada uma das mais antigas "tecnologias" que a humanidade já teve a oportunidade de conhecer embora esta apresentasse características diferentes, feita sobre tabletes de argila, a qual serviu e serve para muitas finalidades, na política, religião, publicidade e literatura. Assim, a escrita, como característica humana, sofre muita influência de seguimentos como a comunidade, família, sociedade e natureza social em sua aquisição pelas crianças, que deve ocorrer de forma dinâmica e interessante, como defende Arena (2010), os professores precisam motivar e incentivar a leitura de imagens, trabalhando a criatividade e realidade das crianças, a fim de chamar sua atenção para tal atividade, sendo respeitadas as limitações de cada indivíduo envolvido no processo educacional como aponta Didonet (2003).

O professor como mediador e incentivador do conhecimento, precisa estar atento para as diferentes características que as crianças possuem e principalmente nas diferentes formas de desenvolvimento e curiosidades de cada uma. Trabalhar na direção da aprendizagem da escrita possibilita melhor qualidade no desenvolvimento de quem aprende a ler e escrever, a leitura e a escrita são primordiais para que os indivíduos exerçam seus direitos, ou como determina Arena (2010), possam trabalhar e participar da sociedade com cidadania, se informar e aprender coisas novas ao longo de toda a vida.

Ao iniciarem a vida escolar, as crianças, em suas casas, assistem televisão, participam de jogos, brincadeiras, escutam músicas, utilizam o celular, computadores e outras atividades sociais de linguagens que também colaboram para desenvolver habilidades que mais tarde só irá aperfeiçoar a realização da leitura. O que caracteriza que mesmo fora da dinâmica escolar, as crianças já têm acesso a diversos recursos tecnológicos, os quais colaboram no desenvolvimento de suas habilidades linguísticas, podendo ser bastante explorado pela escola. Com o intuito de inovar o ensino nos anos iniciais a equipe pedagógica da escola precisa 
desenvolver práticas pedagógicas, com ênfase nas tecnologias, que visam o desenvolvimento e aprendizagem da oralidade, leitura e escrita, simultaneamente, de modo que ofereça um ensino dinâmico e divertido do ponto de vista infantil. Assim, desenvolver nas crianças, o gosto pela leitura e escrita, por meio de atividades lúdicas e recreativas, utilizando as tecnologias, com vistas ao desenvolvimento afetivo, cognitivo, cultural e formação integral das mesmas.

As práticas tecnológicas na educação colaboram significativamente na aprendizagem dos alunos, como os softwares educacionais, que são recursos importantes para melhorar os conhecimentos e aprimorar o desenvolvimento do processo de alfabetização, haja vista que a informática é um recurso tecnológico que disponibiliza aos professores e alunos condições para encontrar um leque infinito de informações, antes apenas presentes nos livros didáticos, o que segundo Pretto (2008, p. 81): “ [...] exige o estabelecimento de novas conexões que situem diante dos complexos problemas enfrentados pela educação." Nessa perspectiva, é importante que professores e equipe pedagógica estejam preparados para selecionar os recursos tecnológicos e informações necessárias para o ensino de uma disciplina específica, uma vez que nem todas as informações disponíveis nos recursos de multimídias e informática são adequadas para o ensino escolar nas series iniciais, visto que, a todo o tipo de conteúdo nas redes, atentar-se essencialmente para informações significativas para a formação escolar.

Para atender os requisitos de oferta de uma educação aliada a tecnologia, a escola precisa ser equipada de recursos suficientes a serem manuseados pelos alunos e professores, no sentido de dinamizar as aulas, auxiliando os alunos na aquisição da leitura, escrita e aprimoramento das suas habilidades cognitivas. Concomitante a necessidade de recursos materiais e equipamentos para o desenvolvimento do processo educacional, de outra forma, segundo Almeida (2000) os profissionais da educação precisam estarem preparados para desenvolver competências, dominar técnicas de programação e softwares para explorar e orientar trabalhos como o alunado.

Um dos grandes problemas do processo de introdução das tecnologias na educação é que os equipamentos digitais são insuficientes para as demandas das escolas do atendimento dos alunos em sala de aula, como por exemplo, sala de informática, datashow, retroprojetor, vídeos, televisão, aparelho de DVD, notebook e computadores. As ferramentas muito utilizadas são projetores de imagem, os celulares dos próprios alunos e computadores na sala de informática, a qual é utilizada em forma de escala agendada para as turmas utilizarem pesquisas e estudos, bem como aprender a manusear as tecnologias como máquina e internet, que segundo Maesta (2011), como as escolas públicas não dispõem de todas as salas de aula informatizadas, faz-se necessário que o professor reserve o espaço do laboratório de informática, a fim de orientar seus alunos a utilizar e pesquisar na internet, com responsabilidade e discernimento e aprendam a distinguir informações relevantes.

Nesse processo há de se considerar o esforço dos professores em função do uso das tecnologias em sala de aula, em favor da maior compreensão do conteúdo, além de despertar o interesse dos alunos por meio de aulas mais ilustrativas, atrativas e dinâmicas, as quais prendem a atenção dos mesmos, possibilitando melhores resultados nas avaliações das 
atividades pedagógicas desenvolvidas. As aulas a partir do uso das tecnologias se tornam mais atraentes para os alunos, até porque as imagens projetadas e o áudio se tornam o foco da aula junto com a ferramenta principal que é a explicação, melhorando o andamento das atividades propostas na sala de aula, quando aluno demonstra maior interesse de pesquisar, principalmente nos celulares e computadores, com aulas mais produtivas.

De um modo geral, o professor e toda a equipe pedagógica precisam estar disponíveis ao desenvolvimento de uma prática pedagógica inovadora, com a construção de propostas, centrada nos recursos tecnológicos, como ferramenta pedagógica, trabalhando conforme a atualidade, realidade e interesse dos alunos. Nesse processo de inovações, quanto ao processo de alfabetização, faz-se necessário interagir momentos com jogos educativos, bingos de nomes, de frases, musicalidade, criação e contação de histórias, dentre outras dinâmicas e recursos tecnológicos, que possibilitam a interação alunos, professor e o conteúdo ensinado. Assim, as práticas pedagógicas nos anos iniciais devem priorizar um ensino dinâmico, prazeroso e divertido por meio de tecnologias lúdicas como os softwares educacionais e os dispositivos móveis, com vistas ao desenvolvimento da oralidade, leitura e escrita, correspondendo às necessidades e aos interesses das crianças, com resultados positivos no sistema de ensino-aprendizagem.

Nessa realidade, a utilização das tecnologias como metodologias pedagógicas em sala de aula, vieram resgatar o interesse, o prazer e o entusiasmo pelo ato de aprender, permitindo ao professor alcançar sucessos, facilitando o desenvolvimento das habilidades e a confiança dos alunos, a fim de atingirem o autoconhecimento no processo de aprendizagem e na vida.

As aulas com o uso das tecnologias de informação, como os computadores são mais dinâmicas e interessantes para as crianças, que têm maior interesse e facilidade em aprender os conteúdos do currículo, de modo que o professor assuma a função de mediador entre os alunos e o conhecimento construído a partir das tecnologias digitais, incluindo também os dispositivos móveis como os tablets e celulares, permitindo a construção de uma aprendizagem autônoma e criativa, diminuindo a evasão escolar, problema enfrentado por muitas escolas. Contudo, a instalação de laboratórios de informática, com rede de internet, ainda não é realidade na maioria das escolas, o que depende de recursos financeiros e compromisso de gestores públicos. O computador é a ferramenta da informática mais utilizada na prática educativa, potencializando capacitação e aperfeiçoamento dos alunos, professores e todas nas atividades escolares.

Através dos computadores é possível desenvolverem-se softwares educativos como as enciclopédias, animações e jogos eletrônicos de Matemática, da tabela periódica, língua e linguagens, mapas cartográficos em 3D. Também é importante citar aplicativos pelos quais os professores enviam vídeos e tarefas digitais aos alunos por torpedos ou notificações em seu celular e tablets. Esses recursos multimídias educacionais possibilitam uma aprendizagem mais prazerosa e interativa aos alunos, os quais aprendem com maior facilidade e interesse, além de facilitar as atividades docentes dos professores. Portanto, a Tecnologia e a Educação cada vez mais caminham para auxiliar o conjunto das atividades pedagógicas, e para o sucesso dessa união há de existir o desenvolvimento de ações educativas favoráveis ao 
processo educacional.

\section{Considerações finais}

A educação faz parte da valorização do indivíduo a partir da consideração de que o processo educativo deve ser ostensivo a qualquer indivíduo, uma vez que esses, em todas as fases da vida, são capazes de aprender, devendo ser desenvolvido preferencialmente de forma gratuita e de qualidade. Assim, surge à preocupação com o desenvolvimento da linguagem oral e escrita, bem como o gosto pela leitura.

Ao longo deste estudo percebeu-se a necessidade de se construir um ambiente dinâmico e divertido do ponto de vista das crianças, a fim de chamar maior atenção para o aperfeiçoamento da linguagem e aquisição da escrita, pois, antes de frequentar a escola, as crianças já participam de atividades sociais de linguagens, quando assistem televisão, participam de jogos, brincadeiras, escutam músicas, utilizam os recursos de informática e internet, que culminará na consolidação da leitura e escrita. Portanto, faz-se necessário que os professores e a equipe pedagógica tenham conhecimento pedagógico para escolher os tipos de tecnologia a serem utilizadas em sala de aula, com função educativa e que atenda aos objetivos propostos, para o aprimoramento da linguagem oral e escrita.

A utilização das ferramentas tecnológicas na prática educativa é de suma importância para um processo de ensino-aprendizagem mais dinâmico, flexível e interessante na visão dos alunos e que colaboram positivamente neste processo, uma prática responsável e consciente destas tecnologias, atende as necessidades dos alunos e comunidade escolar, partindo para formação de sujeitos críticos, participativos nas transformações de sua realidade.

A reflexão quanto à utilização das ferramentas tecnológicas no processo de aprendizagem, por meio da revisão da literatura é uma temática que diversos autores vêm tratando constantemente, apontando a frequência e finalidades de sua utilização por professores e alunos. Desse modo, conclui-se que as ferramentas potencializaram as possibilidades do professor em diversificar os recursos metodológicos em sua prática educativa, a partir de sua utilização com responsabilidade, critério e compromisso com a aprendizagem de seus alunos e assim colaborar na promoção do conhecimento e na melhoria do processo de desenvolvimento da alfabetização.

Nessa ação, o professor precisa, previamente, conhecer as ferramentas tecnológicas a serem praticadas na sala de aula de forma consciente a fim de refletir positivamente nos processos de aprendizagem, quanto à apropriação de conhecimentos. Para isso é fundamental que os professores tenham um mínimo necessário de conhecimento sobre as tecnologias, sobretudo a informática e suas potencialidades afins.

É de suma importância a educação para o uso ético e moral das tecnologias devido os alunos acessam sites e redes de relacionamento. Entretanto, as dificuldades e desafios em utilizar as tecnologias em sala de aula ocorrem devido à quantidade insuficiente de equipamentos e rede de internet que operam com péssima qualidade, além de laboratório de informática sucateado 
para as aulas práticas, por isso, só resta o retorno na utilização de recursos defasados como TV, DVD e jornais, o que gera atraso no aprendizado do aluno na aquisição de novos conhecimentos e habilidades que as tecnologias digitais possibilitam.

Assim, a utilização significativa das tecnologias trará resultados positivos no processo de ensino-aprendizagem, a partir do compromisso consciente de cada ator envolvido neste processo, quanto à formação de cidadãos críticos e reflexível de sua realidade. No que se refere às inovações tecnológicas, é fundamental que todos sejam agentes ativos na sua utilização consciente das tecnologias, naquilo realmente necessário e não se tornem escravos destas.

O presente trabalho foi muito importante, na medida em que oportunizou o aprofundamento dos conhecimentos em relação à utilização de práticas tecnológicas para o aprimoramento da linguagem oral e escrita, com vistas à consolidação de um ensino dinâmico e com melhores resultados na aprendizagem escolar. Portanto, é primordial a construção de um processo de ensino-aprendizagem de qualidade, para o desenvolvimento das habilidades e competências linguísticas, possibilitando a formação de cidadãos críticos, reflexivos e cientes dos seus direitos e deveres na concretização dos objetos propostos e consolidação de seus espaços na sociedade.

\section{REFERÊNCIAS}

ALMEIDA, Maria Elisabeth Bianconcini de. ProInfo: Informática e Formação de Professores. vol. 2 Série de Estudos Educação a Distância Brasília: Ministério da Educação, Seed, 2000.

ANDRADE. A. P. R. O uso das Tecnologias na Educação: Computador e Internet. Brasília, 2011. Disponível em: http://www.fe.unb.br/catedraunescoead/areas/menu/publicacoes/monografias-sobre-tics-naeducacao/o-uso-das-tecnologias-na-educacao-computador-e-internet. Acessado em 25/04/2018.

ARENA, Dagoberto Buim. A literatura infantil como produção cultural e como instrumento de iniciação da criança no mundo da cultura escrita. São Paulo: Cortez, 2010.

AZANHA, José Mário Pires. "Uma reflexão sobre a formação do professor da escola básica". Educação e Pesquisa 30.2 (2004): 369-378.

BRASIL, Constituição (1988). Constituição da República Federativa do Brasil. Brasília: Senado Federal, centro gráfico, 1988.

BRASIL. LDB 9694/96: Lei de Diretrizes e Bases da Educação Nacional. Secretaria de Educação Fundamental, Brasília; MEC/SEF, 1996. 
BRASIL. Referencial Curricular Nacional para Educação Infantil/Ministério da Educação e do Desporto, Secretaria da Educação Fundamental. Brasília: MEC/SEF, 1998.

BRASIL. CONSELHO NACIONAL DE EDUCAÇÃO. Resolução CNE de 2015, disponível em: $\quad$ http://portal.mec.gov.br/docman/agosto-2017-pdf/70431-res-cne-cp-002-03072015pdf/file. Acessado em 31/05/2018.

DIDONET, Vidal. Não há educação sem cuidado In: Revista Pátio de Educação Infantil. Abr/jul: Porto Alegre, 2003.

FREIRE, Paulo. Educação como prática da liberdade. 23. ed. Rio de Janeiro: Paz e Terra, 1999.

FREIRE, Paulo. A importância do ato de ler: em três artigos que se completem. $46^{a}$ ed. São Paulo: Cortez, 2005.

KENSKI, Vani Moreira. Educação e Tecnologias o Novo Ritmo da Informação. $7^{\mathrm{a}}$ ed. Campinas, SP: Papirus, 2011.

LAKATOS, Eva Maria; MARCONI, Marina de Andrade. Fundamentos de metodologia científica. $6^{\text {a }}$. ed. São Paulo: Atlas, 2006.

LAJOLO, Marisa \& ZILBERMAN, Regina. A Formação da Leitura no Brasil. São Paulo: Ática, 1996.

LAJOLO, Marisa. Do mundo da leitura para a leitura do mundo. 6 ed. São Paulo: Ática, 2005 .

LÉVY, Pierre. Cibercultura. (Trad. Carlos Irineu da Costa). São Paulo: Editora 34, 2009.

LIBÂNEO, José Carlos. Educação escolar: políticas, estrutura e organização. 5. ed. São Paulo: Cortez, 2007.

LUCKESI, Cipriano Carlos. Educação, ludicidade e prevenção das neuroses futuras: uma proposta pedagógica a partir da Biossíntese. In: LUCKESI, Cipriano Carlos (org.). Ludopedagogia - ensaios 1; educação e ludicidade. Salvador: ed. Gepel, 2000.

Disponível em: http://www.luckesi.com.br/artigoseducacaoludicidade. Acessado em 06/02/2018.

LUCKESI, Cipriano Carlos. Organização e gestão da escola: teoria e prática. 5. ed. revista e ampliada. Goiânia: Editora Alternativa, 2004.

MAESTA, Valéria. As influências da tecnologia na educação. Ano de publicação: 2011. Disponível em: www.webartigos.com. Acessado em 09/04/2018. 


\section{Revista Docência e Cibercultura}

MERCADO, Luís Paulo Leopoldo. Formação docente e novas tecnologias. Alagoas,1998.

Disponível em: http://www.c5.cl/ieinvestiga/actas/ribie98/210M.html. Acesso em $12 / 06 / 2018$.

MORAN, José Manuel. Novas Tecnologias e Mediação Pedagógica. $6^{\mathbf{a}}$ Ed. Campinas: Papirus, 2000.

PERRENOUD, Philippe. Dez novas competências para ensinar. Porto Alegre: Artes Médicas Sul, 2000 .

PIAGET, Jean. A linguagem e o pensamento da criança. 6 ed. São Paulo: Martins Fontes, 1990.

PRETTO, Nelson de Luca (org.). Globalização \& Organização: mercado de trabalho, tecnologias de comunicação, educação a distância e sociedade monetária. Ijuí: Ed. Unijuí, 1999.

PRETTO, Nelson de Luca. Cultura digital e educação: redes já! In PRETO, N e SILVEIRA, S. A. (org). Além das redes de colaboração: internet, diversidade cultural e tecnologias do poder. Salvador, Edufba, 2008. Disponível em: http://rn.softwarelivre.org/alemdasredes/2008/08/26/lancado-e-disponibilizado-olivro-doalem-das-redes-de-colaboracao/. Acessado em 27/03/2018.

PROINFO: Informática e formação de professores. Brasília: Ministério da Educação, Seed, 2000 .

PRIETO, Lílian Medianeira, TREVISAN, Maria do Carmo Barbosa; DANEZI, Maria Isabel; FALKEMBACK, Gilse A M. O uso das tecnologias digitais em atividades Didáticas nas séries iniciais. Renote Revista Novas Tecnologias na Educação, www.cinted.ufrgs.br/renote, v. 03, n.01, 2005.http://www.seer.ufrgs.br/renote/article/viewFile/13934/7837. Acessado em $05 / 01 / 2018$.

SANTOS, Giselle Mendes dos. O processo de Alfabetização na Educação Infantil: percursos de uma professora-pesquisadora. Monografia (Graduação em Pedagogia) - Departamento de Educação da Universidade do Estado do Rio de Janeiro. São Gonçalo, 2010.

SILVA, Solimar Patriota. Letramento digital e formação de professores na era da web 2.0: o que, como e por que ensinar? Hipertextus Revista Digital, n.8, Jun. 2012. Disponível em: http://www.hipertextus.net. Acedido em 12/05/2018.

SILVA, Bento Duarte da. A inserção das tecnologias de informação e comunicação no currículo - repercussões e exigências na profissionalidade docente. In: MOREIRA, Antônio Flavio Barbosa; MACEDO, Elizabeth Fernandes de (Orgs.) Currículo, práticas pedagógicas e identidades. Porto: Porto Editora, 2002 
SOARES, Magda. Novas práticas de leitura e escrita: Letramento na cibercultura. Educ. Soc., Campinas, vol. 23, n. 81, p. 143-160, dez. 2002. Disponível em: http://www.cedes.unicamp. br, http://www.scielo.br/pdf/es/v23n81/13935. Acessado em 05/01/2018.

TREINTA, FARIAS FILHO, SANT'ANNA et al. (2014). Metodologia de pesquisa bibliográfica com a utilização de método multicritério de apoio à decisão. Production, v. 24, n. 3, p. 508-520, July/Sept. 2014 doi: http://dx.doi.org/10.1590/S010365132013005000078.Disponível

em:

http://www.scielo.br/pdf/prod/v24n3/aop_prod0312.pdf. Acessado em 05/01/2018.

VEIGA, Ilma Passos de Alencastro. Projeto Político Pedagógico: Uma construção possível. São Paulo: Cortez, 2001.

Este é um artigo de acesso aberto distribuído sob os termos da Licença Creative Commons Atribuição Não Comercial-Compartilha Igual (CC BYNC- 4.0), que permite uso, distribuição e reprodução para fins não comerciais, com a citação dos autores e da fonte original e sob a mesma licença. 